\title{
Reseña de: Taillefer, Lidia. La causa de las mujeres en Gran Bretaña a través de sus textos. Madrid: Fundamentos, 2019
}

\author{
Paula FERNÁNDEZ VILLALOBOS \\ Universidad de Málaga, Málaga
}

Entregarse a la causa es iniciar un viaje no solo hacia una sociedad justa e igualitaria, sino también hacia un conocimiento más profundo de la esencia femenina. Del mismo modo, la causa también es sinónimo de liberación, de rotura de cualquier tipo de atadura y sometimiento de la mujer, de la edificación de esa habitación propia que Virginia Stephen Woolf tan sublimemente reclama en sus letras. Las quince autoras que Lidia Taillefer estudia con detalle en este libro, así como los dos aliados de este movimiento, abren nuestros ojos a una realidad que, después de tantos años, aún nos sorprende reconocer. Asimismo, todas estas personalidades, de gran influencia y reconocimiento social, revelan en estas páginas sus inquietudes, sus miedos y parte de su ser, con una intimidad tan humana que, sin esfuerzo, consigue conmover al lector para que este también abrace la causa feminista.

Cuestiones sobre independencia económica (Harriet Hardy Taylor Mill), frustración y desperdicio del talento femenino (Florence Nightingale, Virginia Stephen Woolf), derecho al voto (Barbara Leigh Smith Bodichon), cómo conseguirlo y cómo se alcanzó el mismo (Emmeline y Christabel Pankhurst, Ray Mary Costelloe Strachey), el acceso de la mujer a una formación profesional y a la carrera médica (Elizabeth Garrett Anderson, Elizabeth y Emily Blackwell), la emancipación femenina como un beneficio social (Millicent Garrett Fawcett), la independencia económica y la conquista de un espacio propio (Virginia Stephen Woolf) se recopilan en los textos de este trabajo,

Los contenidos de la revista se publican bajo una licencia de Creative Commons Reconocimiento 4.0 Internacional (CC BY 4.0)

Feminismo/s 34, diciembre 2019, pp. 349-353 
compuesto por dieciséis capítulos en los que, de igual forma, se consideran temas controvertidos como la prostitución (Josephine Elizabeth Grey Butler), la desvirtuación de la representación femenina en la literatura (Anne Isabella Thackeray), la soltería (Harriet Martineau) y el parasitismo sexual de las esposas (Olive Schreiner).

Todos estos escritos manifiestan una voz femenina apenas oída en su tiempo. Se refleja tal hecho con la inclusión de todos los apellidos de sus autoras, tanto de solteras como de casadas. Este pequeño guiño de identidad llama nuestra atención considerablemente y despliega un ensanchamiento de la mirada lectora, la cual va estableciendo relaciones entre los acontecimientos y sucesos relatados con la autoría e importancia que todas estas mujeres desempeñaron en la historia del feminismo. Del mismo modo, el hecho de partir del propio origen de estas defensoras de la causa, acerca al lector a una realidad donde ejercen su influencia otros espacios del pasado que conforman su lucha, voluntad y determinación presentes.

Queda de manifiesto pues que no existe un único feminismo, ya que comprobamos, gracias al orden cronológico de los escritos propuestos, cómo las mujeres van adquiriendo nuevos desempeños y nuevas formas de desarrollar su vida. La nueva mujer, término acuñado por Olive Schreiner, ya no se encuentra representada por la tradicional figura del ama de casa, ese ángel doblegado a la esfera privada que suponen las cuatro paredes de un hogar. Esta ahora sale, busca su lugar en la vida pública y reivindica sus derechos de manera diversa. Encontramos mujeres como Florence Nightingale, las hermanas Blackwell y Elizabeth Garret Anderson que se dedicaron a la sanidad y a promover la inclusión de la mujer en el mundo de la medicina, convirtiéndose además Garret Anderson en la primera doctora estadounidense. Emmeline y Christabel Pankhurst, en cambio, fueron grandes activistas que se dedicaron a salir a las calles a defender sus derechos. Por el contrario, había otro grupo de mujeres, entre las que se encuentra Millicent Garrett Fawcett, que abogaban por un feminismo más liberal y sosegado que se consiguiese con el diálogo y a través de la literatura, tal y como defendía Virginia Stephen Woolf. Incluso es posible contemplar en estos escritos el influjo religioso que mueve a ciertas autoras como Josephine Elizabeth Grey Butler y en especial a Florence Nightingale, la cual presenta en su obra Cassandra una figura de Cristo que si «hubiera sido mujer, no habría podido más que quejarse» (Taillefer 58).

Feminismo/s 34, diciembre 2019, pp. 349-353 
Sin embargo, a pesar de esta diversidad de puntos de vista, todas ellas nos demuestran que solo hay una única causa.

Los vínculos familiares y la amistad se presentan como factores fundamentales en la lucha de estas mujeres por la igualdad. Por un lado, las mujeres que contrajeron matrimonio, lo hicieron con personas que por regla general abrazaban la causa. Este es el caso de Harriet Hardy Taylor Mill, quien con su segundo marido, John Stuart Mill, escribió en colaboración Principles of Political Economy y On Liberty, aunque nunca se le atribuyó tal reconocimiento. Olive Schreiner lo hizo con Samuel Cronwright-Schreiner, el cual añadió además el apellido de su mujer al suyo. El marido de Millicent Garrett Fawcett, la hermana pequeña de Elizabeth Garrett, Henry Fawcett, era profesor de Economía Política, por lo que esta sufragista pudo contar con la ayuda de su esposo para organizar políticamente a las mujeres inglesas de la época, convirtiéndose Millicent en la madre del sufragio femenino.

Por otro lado, muchos de los padres de estas feministas educaron a sus hijas bajo un talante liberal en el que no se realizaban distinciones de sexo. Por ejemplo, el padre de Barbara Leigh Smith Bodichon otorgaba 300 libras anuales a sus hijos ya fuesen varones o mujeres, lo que permitió que ella estudiase arte, se independizase y viajase por Europa. Barbara mantuvo este ideal con su marido, el médico Eugène Bodichon, quien le permitió conservar su apellido de soltera junto al de casada e incluso vivir medio año en Argelia con él y medio año sola en Inglaterra. Algo semejante observamos en Josephine Elizabeth Grey Butler; su padre, John Grey, un liberal que trabajaba por la reforma legislativa, apostó por ofrecer a sus hijos una educación basada en la igualdad. George Butler, un profesor universitario, también feminista, se convirtió en su marido, por lo que la similitud entre ambas es evidente. Harriet Martineau fue igualmente educada para ser independiente y autosuficiente. La diferencia aquí subyace en el hecho de que Harriet nunca se casó. No obstante, tampoco lo lamentó, «soy probablemente la soltera más feliz de toda Inglaterra» (Taillefer 160). Las hermanas Elizabeth y Emily Blackwell escogieron el mismo destino, así como Christabel Pankhurst, la hija mayor de Emmeline Goulden Pankhurst y del abogado reformista y feminista Richard Pankhurst. Como sus padres, Christabel luchó encarecidamente por la causa, llegando a afirmar que, para liberarse de las fuerzas masculinas, era preciso que la mujer tomase decisiones como no casarse ni tener hijos.

Feminismo/s 34, diciembre 2019, pp. 349-353 
El sentimiento cálido de una amistad reconfortó a algunas de estas jóvenes en su lucha por la equidad social. Un ejemplo claro lo encontramos en Millicent Garrett Fawcett y en Ray Mary Costelloe Strachey, dos amigas que creían en un feminismo socialdemócrata y en la valía de la figura femenina en la esfera laboral, educativa y legal. De hecho, sería la misma Ray Strachey quien escribiría la biografía de Garrett Fawcett una vez que esta falleciese. En cambio, Anne Isabella Thackeray y Virginia Stephen Woolf mantuvieron una relación más maternal, siendo Thackeray medio tía de Stephen Woolf y, posteriormente, una madre adoptiva para la misma cuando la hermana de Thackeray (casada con el padre de Virginia) murió. El hecho de que también se muestre en estos escritos un fuerte sentimiento de admiración entre estas mujeres, pone de manifiesto que no es posible lograr un verdadero compromiso político y social sin antes trabajar la responsabilidad emocional, es decir, el respeto y la fascinación constructiva por el trabajo y los avances de la mano amiga, lo que muestra una sororidad temprana que más tarde se convertiría en uno de los pilares fundamentales del feminismo de hoy en día.

Tal y como John Stuart Mill sostenía, «hay mujeres y hombres a quienes la igualdad no les da satisfacción, para quienes no habrá paz mientras una voluntad o deseo no se contemple como suyo propio» (Taillefer 116), por lo que fue primordial para estas mujeres que, en un mundo de hombres, pudiesen contar con el apoyo de aliados que defendiesen con su mismo empeño la causa. La retroalimentación fue recíproca. Observamos por ejemplo que para John Stuart Mill su esposa Harriet Hardy Taylor fue un pilar clave para el desarrollo de sus ideas feministas. En su ensayo La dominación de la mujer, inspirado por Harriet, comprobamos cómo él mismo es consciente de la subordinación total de la mujer al hombre, incluso llega a compararlas con esclavos. Por su parte, el médico Henry Havelock Ellis se centró en otorgar a la causa un nuevo rumbo jamás contemplado previamente, la liberación y el despertar sexual femenino, dos componentes esenciales dentro del feminismo actual de la Tercera Ola. Mientras que antes se contemplaban cuestiones sobre la propiedad y la independencia de la mujer, y sus mejoras educativas y laborales, gracias a Havelock Ellis se adquiere también el objetivo de brindar a la mujer un espacio propio dentro de su sexualidad, donde, por supuesto, haya cabida para el placer y el disfrute.

Feminismo/s 34, diciembre 2019, pp. 349-353 
Finalmente, podemos afirmar que La causa de las mujeres en Gran Bretaña a través de sus textos nos induce a crear un imaginario propio sobre la historia de la mujer. Revela, además, una reivindicación de la figura femenina, una supervivencia íntima de su ser en una esfera social, desconocida y negada para ellas. Precisamente, tal y como hemos comprobado, es esta resistencia a la hostilidad pública lo que ha supuesto su mayor compromiso por la causa, así como lo que ha dejado huella en la memoria histórica. Desafortunadamente, la causa femenina es algo por lo que aún se debe seguir luchando. Es por eso que este trabajo invita al lector a asumir los hechos que aquí se relatan, conservando siempre su vista hacia el horizonte, así como a tomar responsabilidad y consciencia del desarrollo de un porvenir de puertas abiertas para la figura de la mujer.

Feminismo/s 34, diciembre 2019, pp. 349-353 